\title{
Penggunaan Sensor Jarak Ultrasonik dan Sensor Proksimitas Inframerah dengan Metode Scanning dan Triangulasi untuk Mendeteksi Furnitur dan Boneka pada KRPAI Berkaki
}

\author{
Daniel Santoso', Deddy Susilo², Adi Gunawan ${ }^{3}$ \\ Program Studi Teknik Elektro, \\ Fakultas Teknik Elektronika dan Komputer, \\ Universitas Kristen Satya Wacana, Salatiga \\ 11daniel.santoso@staff.uksw.edu, 2deddy.susilo@staff.uksw.edu, \\ 3612012011@student.uksw.edu
}

\begin{abstract}
Ringkasan
Berdasarkan evaluasi internal pelaksanaan KRI 2015, robot pemadam api berkaki tim R2C UKSW tidak dapat secara akurat mendeteksi halangan berupa boneka dan furnitur. Oleh karena itu dikembangkan teknik baru yang diharapkan lebih akurat, yaitu menggunakan 8 sensor jarak ultrasonik yang diatur menyerupai oktagon dan 2 buah sensor proksimitas inframerah yang dipasang sejajar pada jarak $11.5 \mathrm{~cm}$. Untuk sensor jarak ultrasonik pendeteksian menggunakan metode scanning sedangkan sensor proksimitas inframerah menggunakan metode triangulasi. Robot juga diprogram supaya tidak melewati daerah yang terdapat boneka dalam perjalanan menuju home setelah memadamkan api. Hasil pengujian sebanyak 60 kali, tingkat keberhasilan robot dalam mendeteksi boneka sebesar $98.3 \%$, tingkat keberhasilan robot dalam memilih rute yang benar 93.3\%. Pengujian pendeteksian furnitur dilakukan sebanyak 120 kali dengan tingkat keberhasilan $89.2 \%$.
\end{abstract}

Kata kunci: robot berkaki, sensor jarak ultrasonik, sensor proksimitas inframerah, scanning, triangulasi

\section{Pendahuluan}

Berdasarkan evaluasi internal pelaksanaan KRI 2015, robot pemadam api berkaki memiliki masalah dalam mendeteksi halangan dan dinding. Halangan berupa boneka dan furnitur tidak terdeteksi sehingga ditabrak oleh robot sedangkan dinding terdeteksi sebagai boneka sehingga robot berputar - putar terus. Tertabraknya halangan oleh robot akan berakibat diskualifikasi sedangkan robot yang berputar - putar terus menyebabkan robot tidak dapat menyelesaikan misi pemadaman api.

Berdasarkan permasalahan di atas, pada penelitian ini dikembangkan sebuah algoritma untuk mendeteksi halangan secara akurat pada robot pemadam api berkaki R2C UKSW. Diharapkan algoritma pendeteksian halangan yang telah diperbaiki dapat membuat robot berkaki pemadam api R2C UKSW menjadi lebih kompetitif pada KRPAI mendatang. 


\section{Kajian Pustaka dan Landasan Teori}

Beberapa robot dengan tujuan sejenis telah dikembangkan dengan menggunakan berbagai macam algoritma pendeteksian halangan. Pada bab ini akan dibahas beberapa di antaranya sebagai bahan acuan dan perbandingan.

\subsection{Kajian Pustaka}

\subsubsection{Ultrasonic and Infrared Sensors Performance in a Wireless Obstacle Detection System [1]}

Pada penelitian ini, dirancang sebuah purwarupa alat yang dapat mendeteksi halangan menggunakan sensor ultrasonik dan sensor inframerah. Alat ini dimaksudkan bagi orang yang sudah tua dan bagi yang memiliki kesulitan dalam melihat sehingga memudahkan mereka untuk mengetahui bila di depannya ada penghalang. Hasil percobaan menunjukkan bahwa purwarupa alat sudah mampu mendeteksi benda dengan warna dan material yang berbeda-beda dengan tingkat akurasi mencapai $95 \%$.

\subsubsection{Desain Perangkat Lunak Pengukuran Jarak antara Bidang Kamera dan Objek Target Menggunakan Metode Triangulasi Komputer Stereo Vision [2]}

Pada penelitian ini, dirancang sebuah perangkat lunak untuk mengukur jarak kamera dan objek sebenarnya dengan metode triangulasi komputer stereo vision. Komputer stereo vision adalah metode mengekstraksi informasi 3 dimensi dari citra digital yang didapat dari kamera dengan cara membandingkan suatu objek dari 2 sudut pandang yang berbeda. Dengan menggunakan stereo vision maka penggunaan sensor lain pada robot yang berkaitan dengan navigasi dapat dikurangi. Objek yang diukur jaraknya berupa kubus hitam dengan latar berupa layar putih. Pengambilan citra objek menggunakan webcam dengan konfigurasi membentuk segitiga. Hasilnya didapat bahwa webcam dapat mendeteksi layaknya mata manusia dimana bila terlalu dekat atau jauh citra yang ditangkap akan terlihat kabur. Berdasarkan percobaan, didapatkan citra paling optimal bila objek berada sejauh $36 \mathrm{~cm}$ dari webcam.

\subsection{Landasan Teori}

\subsubsection{Metode Triangulasi}

Gambar 1 menunjukkan penerapan metode triangulasi pada robot untuk mendeteksi suatu objek. Pengaturan letak sensor untuk mendeteksi objek secara triangulasi dapat ditentukan dengan menghitung koordinat dan jarak yang diinginkan dari robot ke boneka agar robot tidak menabrak boneka. Dari sudut deteksi maksimal sensor infrared proximity kiri didapat sudut $\alpha$, dan sensor infrared proximity kanan mendapatkan sudut $\beta$. 


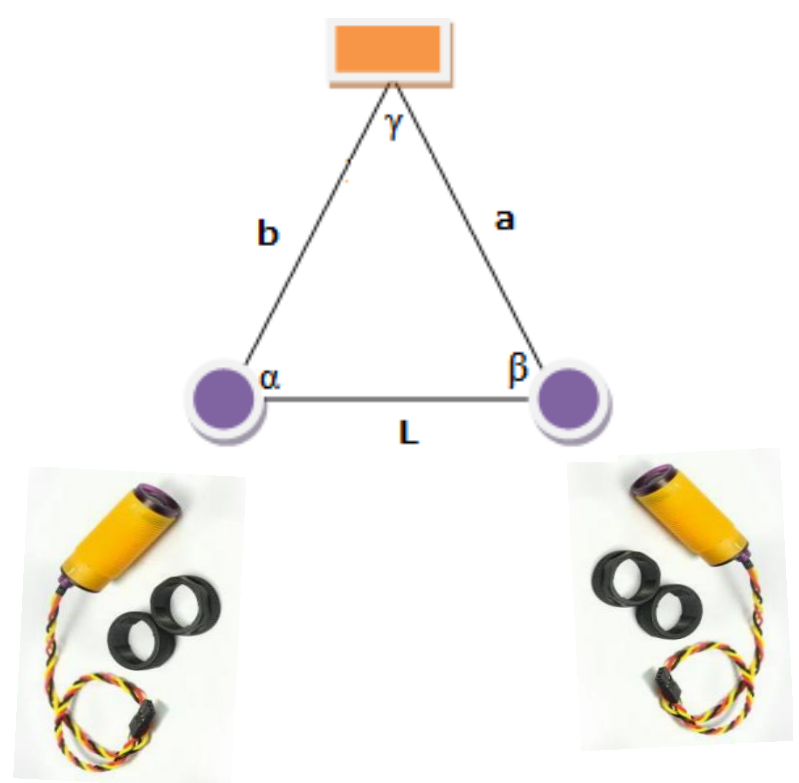

Gambar 1. Prinsip pendeteksian objek secara triangulasi menggunakan sensor optik

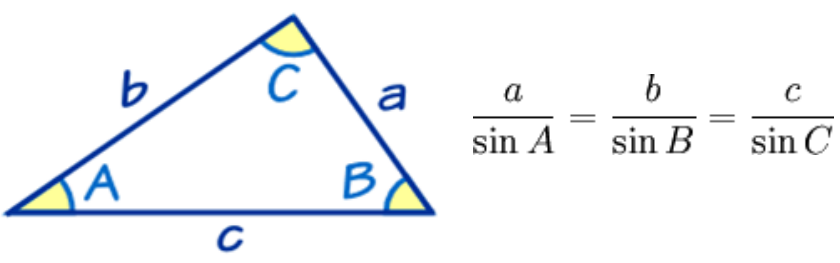

Gambar 2. Aturan sinus pada segitiga sembarang

Untuk mencari jarak antara kedua sensor optik dapat dilakukan dengan mengingat aturan sinus yang dapat diilustrasikan pada Gambar 2. Dengan menggunakan aturan sinus tersebut maka dapat ditentukan jarak antara dua sensor optik (l) dengan menggunakan persamaan - persamaan berikut ini.

$$
\begin{gathered}
\frac{a}{\sin \alpha}=\frac{1}{\sin \gamma} \\
\frac{d}{\sin \beta}=\frac{a}{\sin 90} \\
\frac{d}{\sin \alpha \sin \beta}=\frac{1}{\sin \gamma}
\end{gathered}
$$

Setelah melalui beberapa operasi aritmatika didapatkan persamaan akhir untuk menentukan nilai $l$ yaitu.

$$
l=\frac{d \times \sin \gamma}{\sin \alpha \sin \beta}
$$

$d=$ jarak robot ke objek.

$l=$ jarak antar dua buah sensor infrared proximity.

$\gamma=$ sudut yang terbentuk dari sinar pantul dan sinar datang.

$\alpha=$ sudut antara sensor dengan sisi robot. 


\subsubsection{Metode Scanning}

Metode scanning adalah metode untuk mendeteksi suatu objek dengan cara mengambil data secara kontinu dengan orientasi berbeda - beda. Metode ini dapat diterapkan untuk tujuan pengukuran jarak maupun mapping, yaitu pemetaan kontur dinding ruang dan objek di sekitar robot. Untuk melakukan scanning ini umumnya digunakan sensor ultrasonik. Gambar 3 menunjukkan ilustrasi metode scanning menggunakan sensor ultrasonik. Dari gambar sebelah kanan terlihat bahwa waktu pantulan gelombang ultrasonik akan bervariasi seiring dengan karakteristik halangan di sekitar robot.
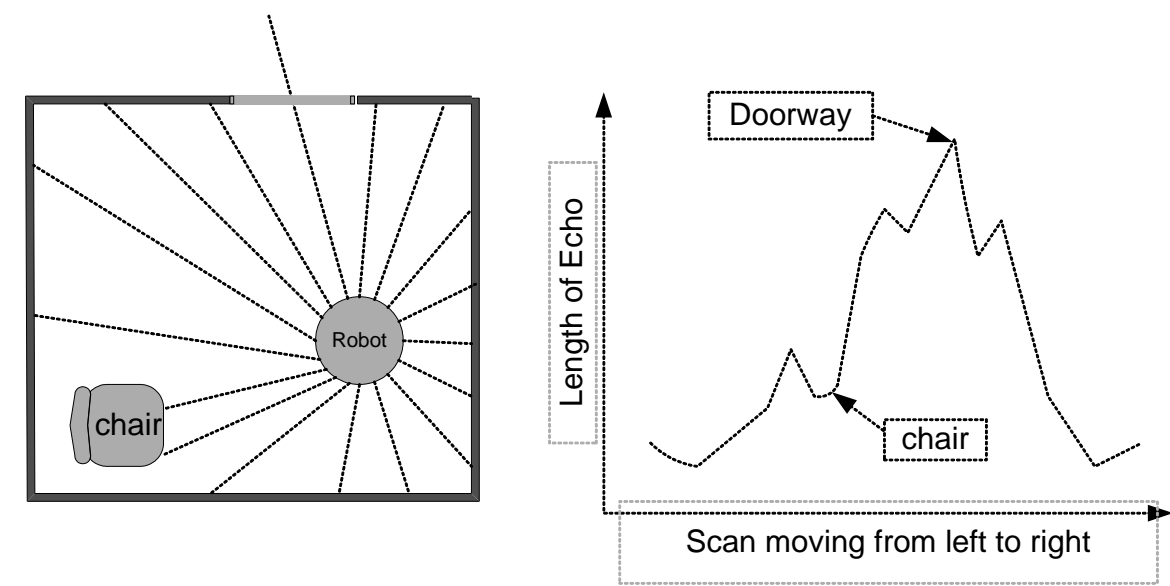

Gambar 3. Metode scanning diterapkan pada robot yang berada dalam ruangan berpintu dan terdapat sebuah objek di dalamnya [3]

\section{Perancangan dan Penerapan}

Sebagaimana umumnya sebuah robot, sistemnya akan terdiri dari mekanik, perangkat keras dan perangkat lunak. Titik berat penelitian ini pada pengembangan dan evaluasi kinerja metode triangulasi dan scanning untuk mendeteksi halangan berupa menghindarinya, meskipun demikian hal mekanik dan perangkat keras tetap akan dibahas secara ringkas untuk memberikan pemahaman yang lebih utuh.

\subsection{Gambaran Mekanik Robot}

Mekanik robot yang digunakan dalam penelitian ini merupakan mekanik yang sama dengan yang digunakan tim robot UKSW untuk bertanding dalam KRPAI 2015. Basisnya adalah robot berkaki enam dengan dimensi panjang tinggi $29 \mathrm{~cm}$, lebar $28 \mathrm{~cm}$, dan tinggi $26 \mathrm{~cm}$ yang terbuat dari kombinasi alumunium dan aklirik. Realisasinya seperti yang terlihat pada Gambar 4. 


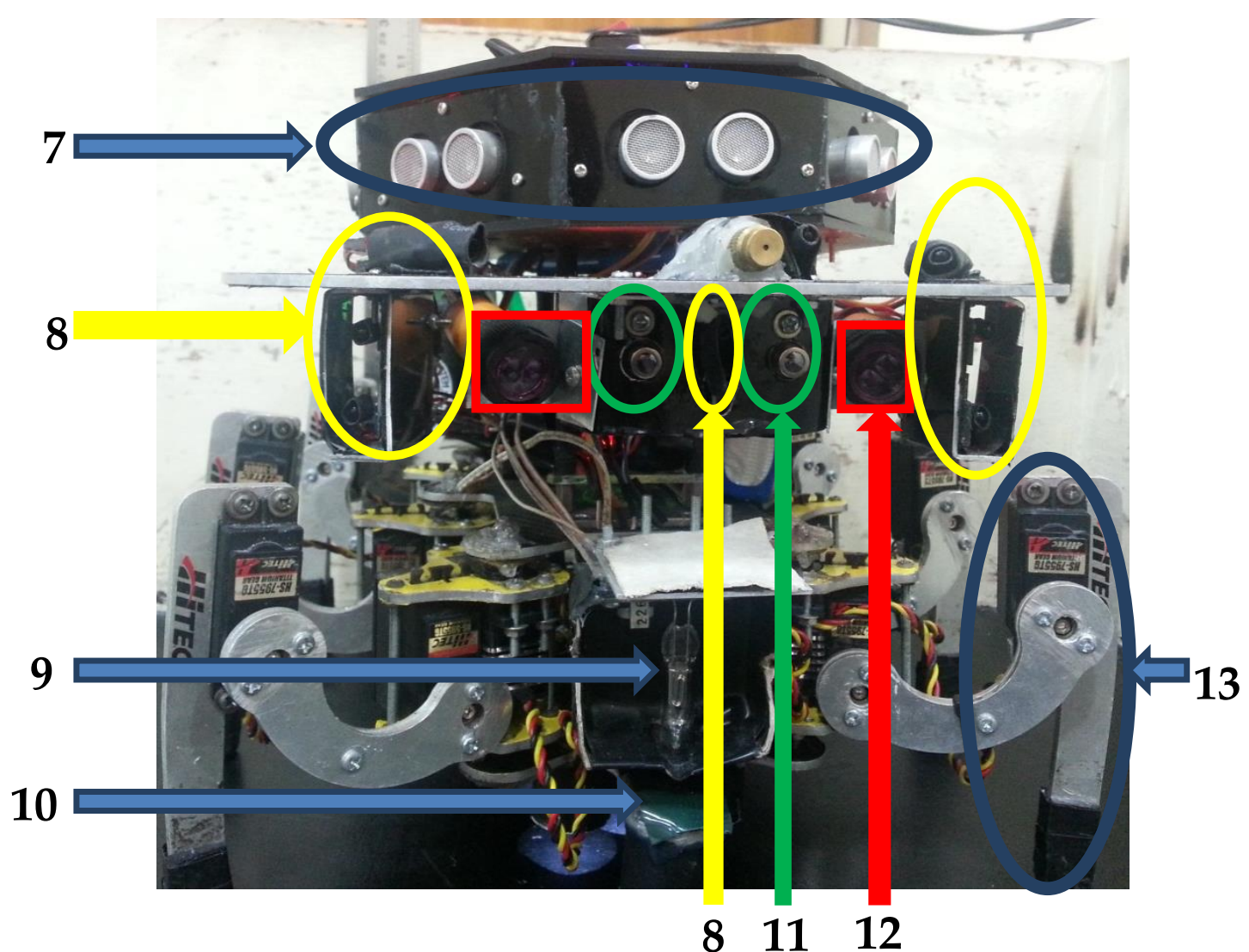

Gambar 4. Realisasi robot berkaki enam pemadam api

Robot pemadam tersebut mempunyai bagian - bagian sebagai berikut.

1. Tombol stop

2. Mikrofon untuk aktivasi bunyi

3. LED indikator mikrofon dan garis

4. Tombol start

5. LED indikator boneka

6. Pemadam api

7. Sensor jarak ultrasonik

8. Sensor api inframerah

9. Sensor api ultraviolet

10. Sensor fotodioda

11. Sensor thermal inframerah

12. Sensor proksimitas inframerah

13. Kaki robot

Bagian depan robot digunakan untuk menempatkan 2 buah sensor thermal inframerah TPA81, 3 buah sensor api inframerah, dan dua buah sensor proksimitas inframerah. Di atas deretan sensor tersebut terdapat kepala robot berbentuk oktagonal octagon dikarenakan tempat meletakkan 8 buah sensor jarak ultrasonik SRF04.

Tungkai kaki - kaki robot dibuat menggunakan rangka ganda agar kuat menyangga beban robot dan untuk menghasilkan pergerakan yang lebih mantap. 


\subsection{Perangkat Keras Robot}

Pengendalian robot menggunakan skema multi - prosesor dan modul penggerak kaki independen. Mikrokontroler master menggunakan Atmega324, mengendalikan dua buah mikrokontroler slave Atmega 324 dan Atmega8. Pengendalian deretan sensor jarak ultrasonik dilakukan oleh mikrokontroler slave Atmega 324 sedangkan mikrokontroler slave Atmega 8 menangani komunikasi antara mikrokontroler master dan modul penggerak motor servo kaki SSC - 32. Gambar 5 menunjukkan diagram blok perangkat keras robot.

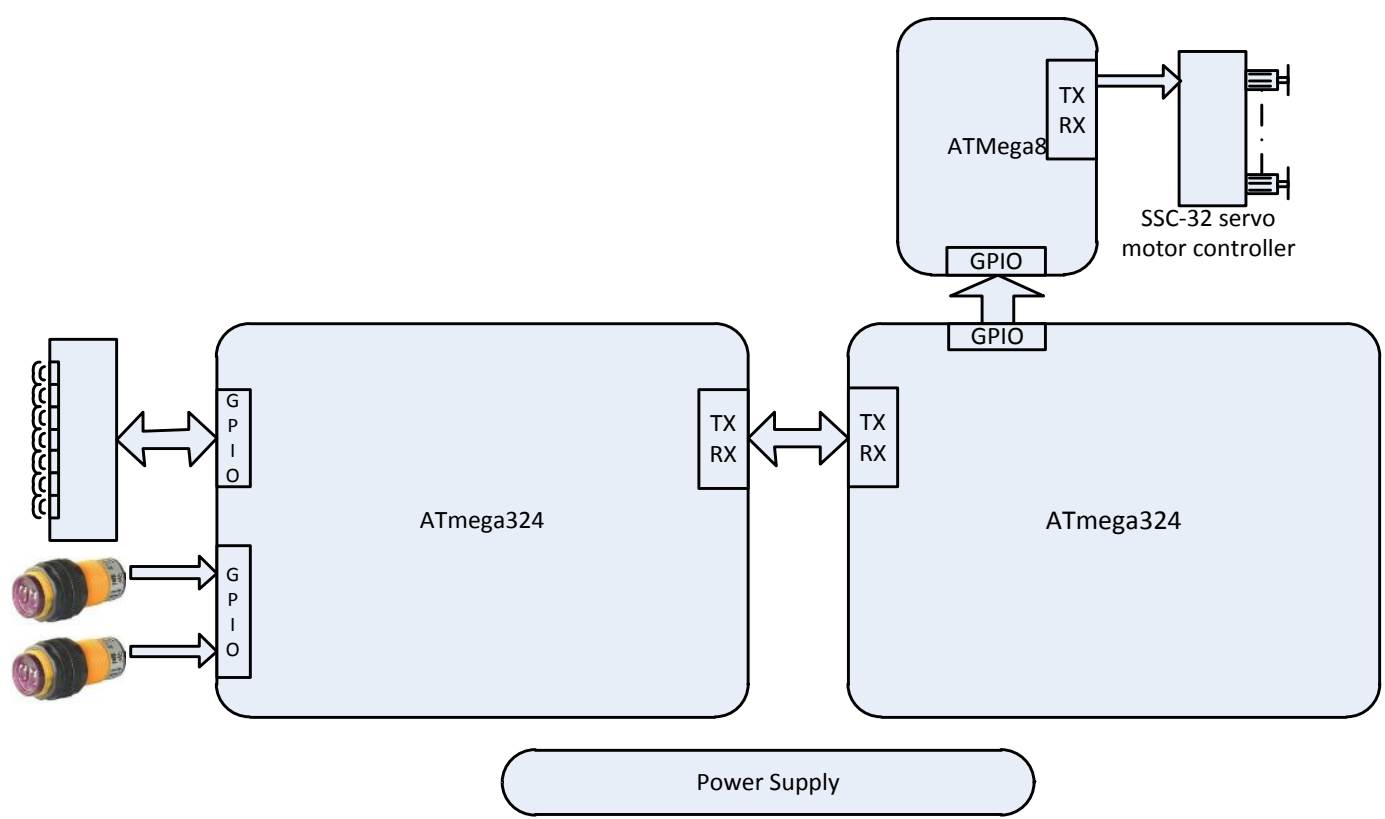

Gambar 5. Diagram blok perangkat keras robot pemadam api berkaki bagian yang berhubungan dengan penerapan algoritma pendeteksian halangan

Ada dua macam sensor yang digunakan oleh robot ini untuk mengetahui kondisi sekitarnya, yaitu sensor jarak ultrasonik dan proksimitas inframerah. Sensor ultrasonik yang berjumlah delapan buah buah bertipe SRF04 yang dapat mendeteksi halangan dalam jangkauan $3 \mathrm{~cm}-3 \mathrm{~m}$ menggunakan pantulan gelombang ultrasonik. Robot sangat bergantung pada sensor ini dalam menyusuri dinding. Pembacaan sensor ini tidak terpengaruh oleh adanya handicap berupa peredam bunyi dan cermin di lapangan. Sensor proksimitas menggunakan pantulan cahaya inframerah dalam menentukan jarak sensor terhadap halangan. Jarak deteksinya dapat diatur antara $3-80 \mathrm{~cm}$. Tujuan utama penggunaan sensor ini adalah untuk mendeteksi adanya halangan berupa boneka anjing yang biasanya diletakkan di lorong sebagai handicap. Jarak antara dua buah sensor proksimitas ini ditentukan dengan menggunakan Persamaan 4 dengan mengambil nilai $\mathrm{d}=6 \mathrm{~cm}, \alpha=15^{\circ}, \beta=15^{\circ}$, dan $\gamma=15^{\circ}$ sehingga didapatkan $\mathrm{l}=11.5 \mathrm{~cm}$.

Robot membutuhkan motor servo sebanyak 18 buah yang harus bergerak secara harmonis dalam melakukan suatu manuver tertentu. Untuk itu diperlukan suatu pengendali independen untuk membantu kerja pengendali utama dalam mengendalikan gerakan motor servo dalam jumlah banyak secara harmonis. Dalam penelitian ini digunakan modul pengendali independen motor servo SSC-32 yang memiliki 32 kanal pengendalian motor servo dengan berbagai mode. 


\subsection{Perangkat Lunak Pengendali Robot}

Perangkat lunak yang akan dibahas pada dasarnya ada mengandung 2 algoritma yaitu algoritma untuk mendeteksi boneka dan algoritma untuk mendeteksi furnitur, tetapi dalam penerapannya dibuat menjadi satu kesatuan. Gambar 6 menunjukkan diagram alir perangkat lunak tersebut.

Untuk mendeteksi boneka, robot harus dapat memasuki daerah boneka yang ditentukan dengan nilai bacaan dari sensor jarak ultrasonik, baru kemudian menggunakan kedua sensor proksimitas inframerah. Daerah tersebut kemudian ditandai sehingga sebisa mungkin tidak melewati daerah tersebut untuk yang kedua kalinya. Hal ini dilakukan untuk meminimalisir kemungkinan bila terjadi error yang dapat menyebabkan robot menabrak boneka. Robot harus bertemu boneka setidaknya sekali untuk dapat mengetahui letak dari boneka tersebut.

Setelah memadamkan api, ketika robot akan kembali ke home. Robot sudah mengenali letak boneka, oleh karena itu ketika robot mendeteksi perempatan (yang dideteksi dengan cara mengecek sensor jarak ultrasonik depan, kanan, kiri, dan belakang) maka robot akan memilih jalan mana yang bebas dari boneka.

Gambar 7 (kanan) menunjukkan kemungkinan letak boneka yang diberi tanda angka 1, 2, dan 3 dimana pada setiap pertandingan hanya ada satu kemungkinan lokasi boneka. Contoh jenis boneka ditunjukkan pada Gambar 7 (kiri).

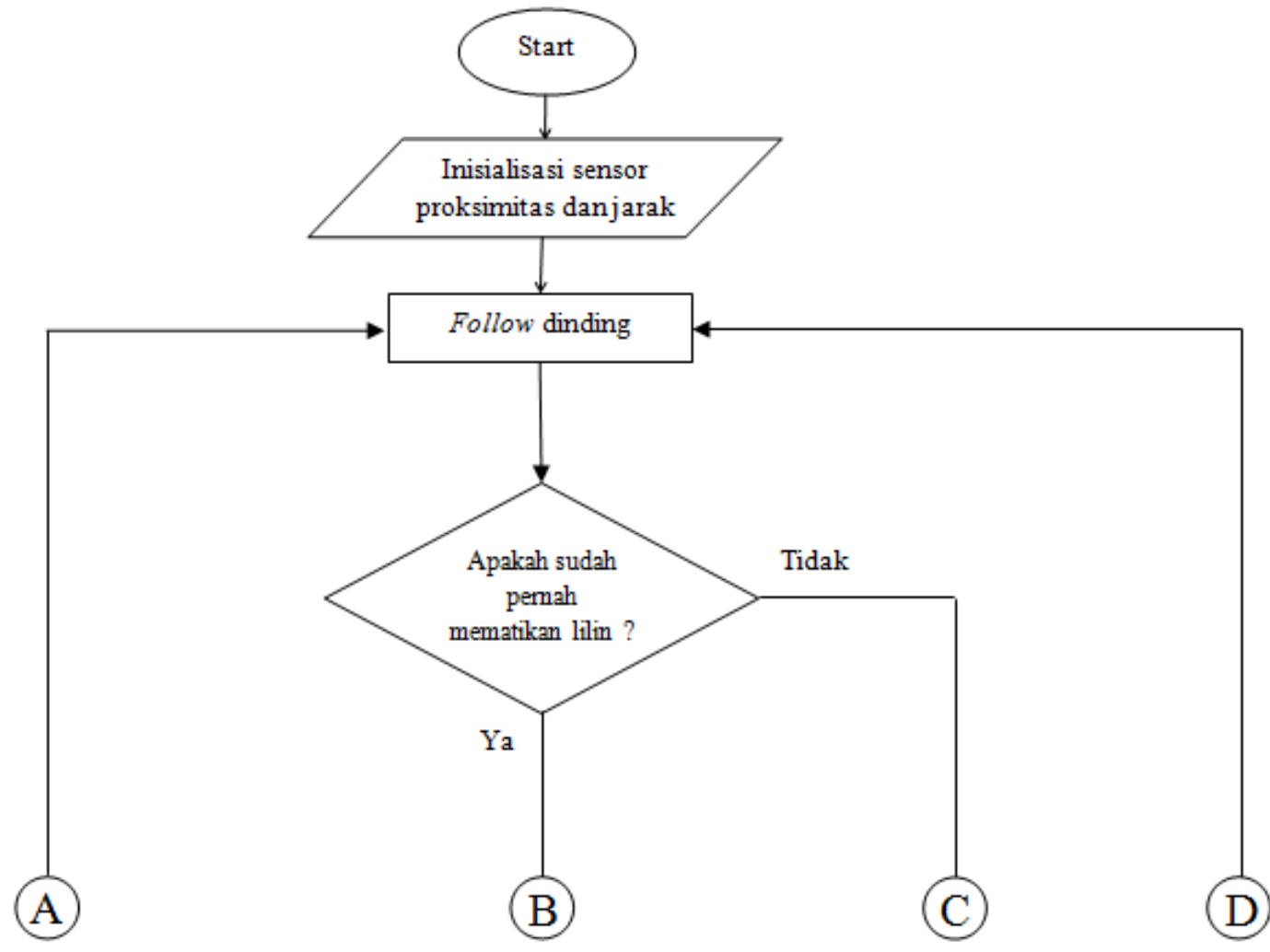

Gambar 6. Diagram alir algoritma pendeteksian boneka dan furnitur pada robot pemadam api berkaki R2C (bagian 1) 


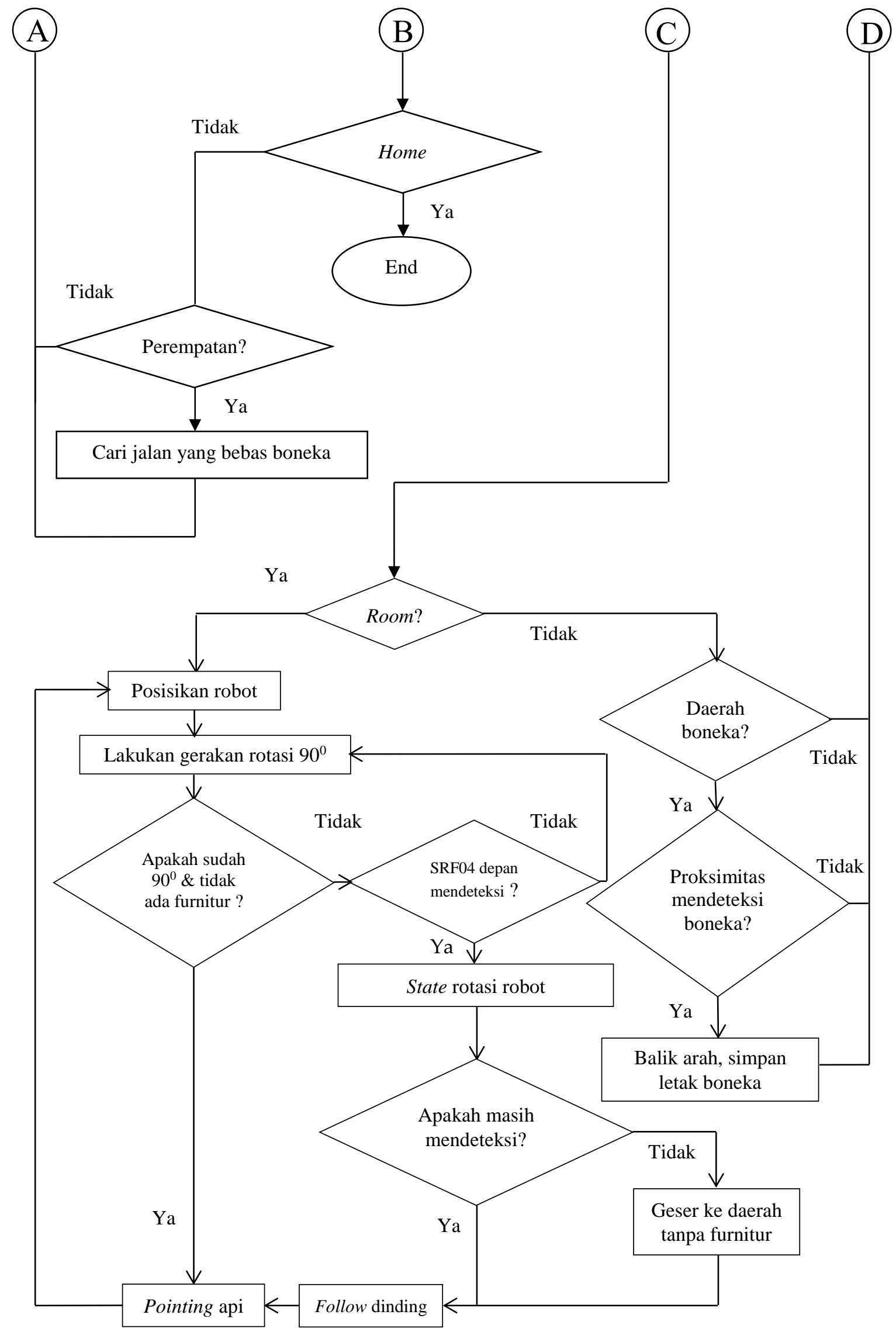

Gambar 6. Diagram alir algoritma pendeteksian boneka dan furnitur pada robot pemadam api berkaki R2C (bagian 2) 

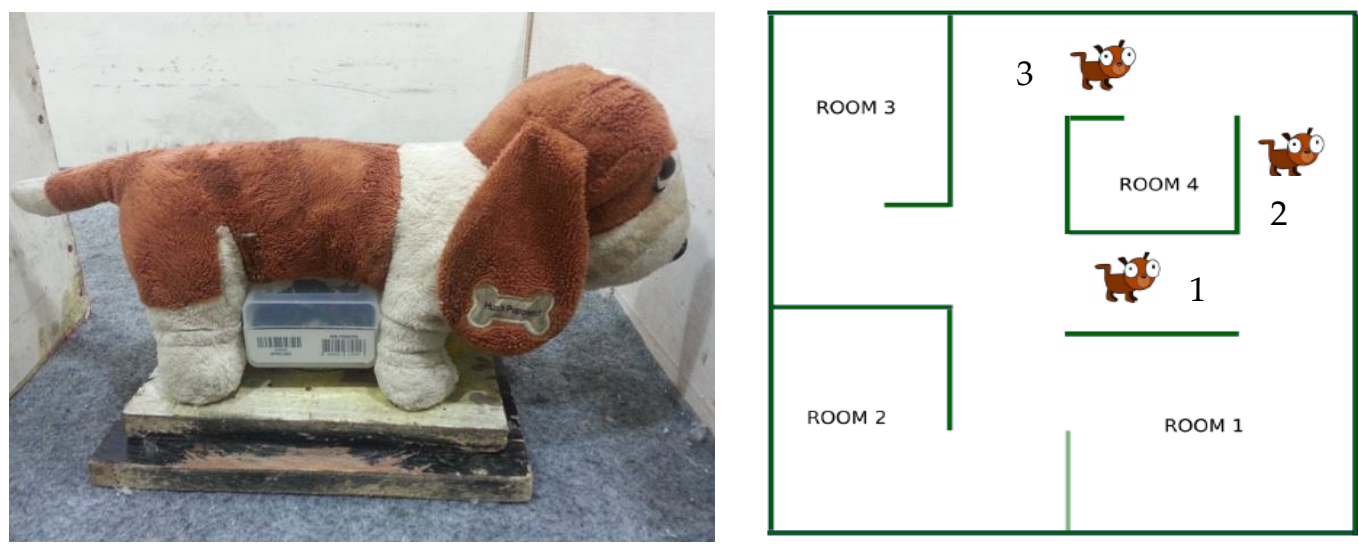

Gambar 7. Contoh boneka dan kemungkinan lokasinya di map pertandingan

Untuk mendeteksi furnitur digunakan metode scanning dimana robot akan melakukan gerakan rotasi sambil mengambil data dari sensor jarak ultrasonik depan. Gerakan rotasi tersebut dibagi menjadi 2 tahap untuk menentukan daerah 1 atau 2 . Ketika di suatu daerah terdapat furnitur maka nilai balikan dari sensor jarak akan bernilai kecil dan kurang dari batas yang telah ditentukan. Batas nilai tersebut didapat dari jarak terpendek ketika robot menghadap tembok. Batas tersebut dibuat berbeda untuk daerah 1 dan 2 agar furnitur pada jarak terjauh tetap dapat terdeteksi oleh robot. Pembagian tiap room yang dimasuki menjadi 2 bagian dengan ketentuan sesuai Gambar 8.
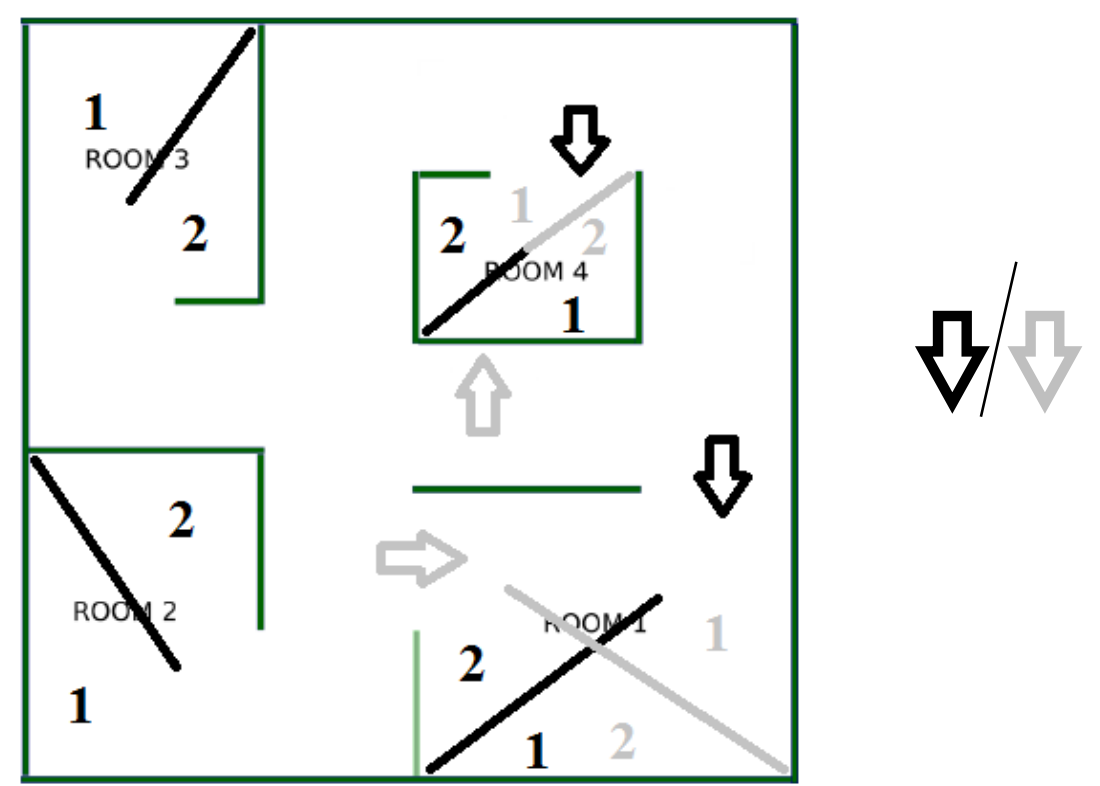

Arah Masuk Robot

Gambar 8. Contoh boneka dan kemungkinan lokasinya di map pertandingan

Panah dan garis hitam menandakan robot masuk room 1 dari pintu yang menghadap ke atas beserta pembagian daerahnya sedangkan panah abu-abu robot masuk room 1 dari pintu di sebelah kiri beserta pembagian daerahnya. Demikian juga dengan room 4, panah 
hitam robot masuk dari pintu yang menghadap ke atas sedangkan panah abu-abu robot masuk dari pintu yang menghadap ke bawah.

Ketika sensor jarak ultrasonik mendeteksi adanya furnitur di depan robot pada daerah sesuai dengan tahap rotasi robot tersebut maka robot akan berhenti berotasi dan robot akan menentukan kearah mana akan melakukan follow. Bila furniture tersebut terdapat di tengah maka robot dapat melakukan follow kanan maupun ke kiri..

\section{Pengujian dan Pembahasan}

Evaluasi kinerja robot dilakukan untuk menguji efektivitas algoritma dan metode triagulasi menggunakan 2 sensor jarak inframerah. Ada dua macam pengujian, pertama pengujian kemampuan robot untuk mendeteksi dan menghindari boneka, ke - dua pengujian kemampuan robot untuk mendeteksi furnitur.

\subsection{Pengujian Robot Mendeteksi dan Menghindari Boneka}

Pengujian robot dalam mendeteksi boneka menggunakan LED sebagai penanda dimana boneka tersebut berada. LED warna merah menandakan boneka ada di daerah 1 , LED warna hijau berarti boneka di daerah 2, dan LED warna biru boneka berada di daerah 3 seperti ditunjukkan pada Gambar 9.

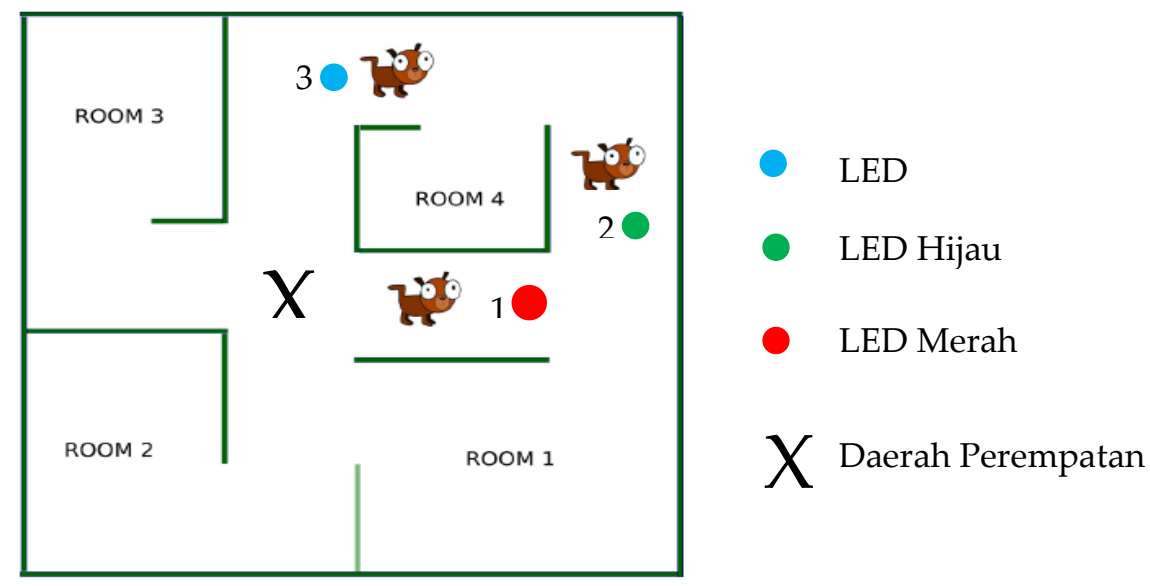

Gambar 9. LED penanda lokasi boneka

Pengujian algoritma menghindari boneka dilakukan dengan menggunakan robot yang bergerak secara otomatis. Robot tersebut diprogram agar dapat menelusuri dinding dan bila menemukan boneka akan melakukan gerakan berputar menghindari boneka tersebut serta menyimpan lokasi boneka tersebut. Ketika robot akan pulang ke home, robot akan memilih rute yang tidak terdapat boneka ketika berada di perempatan .

Robot start dari room 4 dengan pintu menghadap ke atas kemudian menelusuri dinding sampai mendeteksi garis yang merupakan penanda pintu pada sebuah room. Kemudian robot bergerak ke arah kiri dan mendeteksi adanya boneka pada daerah 3 . Selanjutnya robot berputar balik untuk menghindari boneka tersebut sekaligus menyalakan LED warna biru yang menandakan ada boneka di daerah 1. Informasi ini akan disimpan yang selanjutnya digunakan sebagai referensi ketika robot akan balik home. Robot selanjutnya akan mengelilingi lapangan dan memadamkan api di room. Pengujian akan dinyatakan gagal apabila robot menggeser boneka lebih dari $1 \mathrm{~cm}$ atau 
bahkan melewati boneka, demikian juga ketika robot memilih rute yang salah dalam dalam perjalanan menuju home. Gambar 10 menunjukkan skenario pengujian pertama.

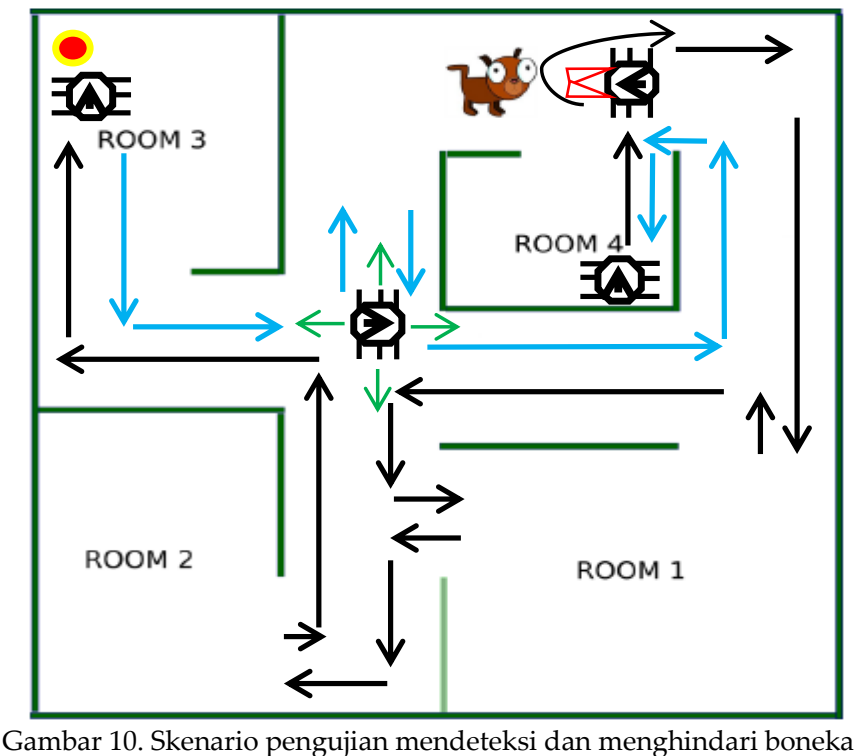

Pengujian ini dilakukan sebanyak 10 kali untuk setiap konfigurasi letak boneka yang berbeda, dimana ada 3 kemungkinan letak boneka yaitu daerah 1, 2, dan 3 serta untuk 2 jenis boneka yang berbeda. Total pengujian pada bagian ini adalah sebanyak 60 kali. Hasilnya dapat dilihat pada Tabel 1. Pengujian yang berhasil diberi tanda centang $(\checkmark)$ sedangkan pengujian yang gagal diberi tanda silang $(\mathbf{X})$.

Tabel 1. Hasil pengujian robot dalam mendeteksi dan menghindari boneka

\begin{tabular}{|c|c|c|c|c|c|c|c|c|c|c|c|c|}
\hline & Jenis & & \multicolumn{10}{|c|}{ Percobaan Ke- } \\
\cline { 5 - 13 } No & Boneka & Daerah & 1 & 2 & 3 & 4 & 5 & 6 & 7 & 8 & 9 & 10 \\
\hline 1 & 1 & 1 & $\checkmark$ & $\checkmark$ & $\checkmark$ & $\checkmark$ & $\checkmark$ & $\checkmark$ & $\checkmark$ & $\checkmark$ & $\checkmark$ & X \\
\hline 2 & 1 & 2 & $\checkmark$ & $\checkmark$ & $\checkmark$ & $\checkmark$ & $\checkmark$ & $\checkmark$ & $\checkmark$ & $\checkmark$ & $\checkmark$ & $\checkmark$ \\
\hline 3 & 1 & 3 & $\checkmark$ & $\checkmark$ & $\checkmark$ & $\checkmark$ & $\checkmark$ & $\checkmark$ & $\checkmark$ & $\checkmark$ & $\checkmark$ & X \\
\hline 4 & 2 & 1 & $\checkmark$ & $\checkmark$ & $X$ & $\checkmark$ & $\checkmark$ & $\checkmark$ & $\checkmark$ & $\checkmark$ & $\checkmark$ & $\checkmark$ \\
\hline 5 & 2 & 2 & $\checkmark$ & $\checkmark$ & $\checkmark$ & $\checkmark$ & $\checkmark$ & $\checkmark$ & $X$ & $\checkmark$ & $\checkmark$ & $\checkmark$ \\
\hline 6 & 2 & 3 & $\checkmark$ & $X$ & $\checkmark$ & $\checkmark$ & $\checkmark$ & $\checkmark$ & $\checkmark$ & $\checkmark$ & $\checkmark$ & $\checkmark$ \\
\hline
\end{tabular}

Pada tabel di atas terlihat bahwa dengan menggunakan boneka jenis 1 robot gagal menjalankan tugasnya untuk daerah 1 dan 3 sebanyak masing-masing 1 kali. Untuk pengujian menggunakan boneka jenis 2, robot tidak berhasil melakukan tugasnya dengan baik pada boneka yang terletak pada daerah 1, 2, dan 3 sebanyak masing-masing 1 kali dari 10 kali percobaan.

Penyebab - penyebab kegagalan dapat diidentifikasi sebagai berikut. Pertama, robot terlambat mendeteksi boneka karena peletakan boneka sedemikian rupa sehingga tinggi boneka menjadi tidak sesuai peraturan. Ke - dua robot gagal mengenali perempatan, sehingga robot tidak dapat menjalankan algoritma untuk menghindari boneka. Ke - tiga, robot melewatkan garis penanda pintu sehingga tidak mengenali room yang dikunjungi. sehingga gagal untuk kembali tanpa menemui boneka lagi. Kecacatan pada map pengujian berupa persambungan dinding yang kurang rapat juga menjadi salah satu faktor robot gagal dalam pengujian. 


\subsection{Pengujian Robot Mendeteksi Furnitur}

Pengujian dilakukan dengan menggunakan robot yang bergerak secara otomatis dari room 4 kemudian keluar menemukan boneka dan berbalik dan melanjutkan follow kiri pada dinding. Ketika memasuki room 1 maka robot akan melakukan scanning untuk mencari letak furnitur apakah berada di daerah 1 atau 2. Penanda daerah tersebut menggunakan sebuah penampil 7-segmen. Langkah selanjutnya adalah robot menentukan akan follow ke kanan atau kiri tergantung letak furnitur tersebut.

Pengujian dinyatakan gagal apabila robot salah mendeteksi ada atau tidaknya furnitur maupun salah menentukan daerah furnitur. Robot juga harus dapat melakukan manuver yang tepat sesuai dengan lokasi furnitur yang dideteksi. Ilustrasi pengujian ditunjukkan pada Gambar 11.

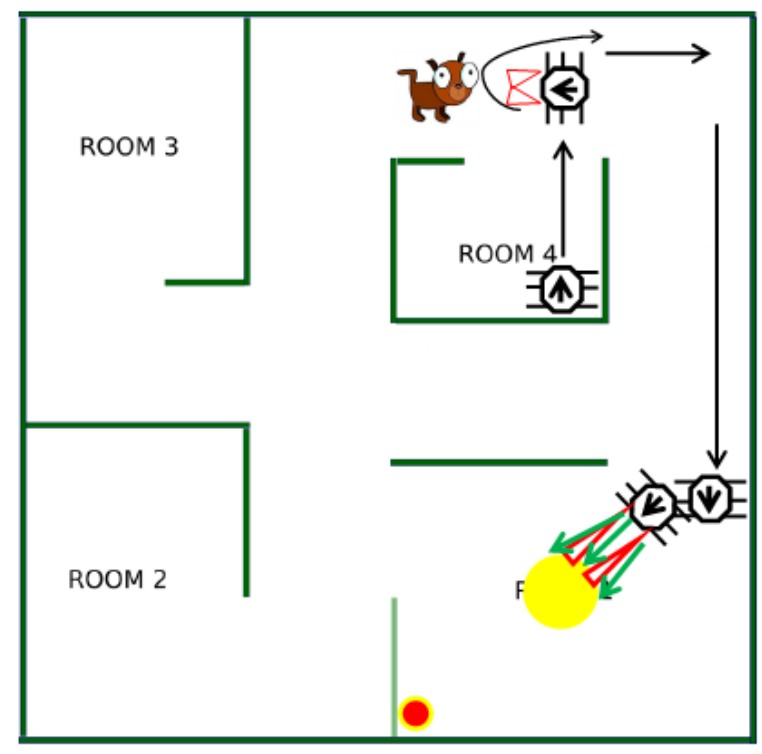

Gambar 11. Skenario pengujian mendeteksi dan menghindari furnitur

Pengujian dilakukan sebanyak 10 kali untuk 4 room (terdapat 6 konfigurasi) yang berbeda dan sebanyak 2 macam peletakan furnitur tersebut (di daerah 1 dan daerah 2). Total pengujian yang dilakukan sebanyak 120 kali. Hasilnya dapat dilihat pada Tabel 2. Pengujian yang berhasil diberi tanda centang $(\checkmark)$ sedangkan pengujian yang gagal diberi tanda silang $(\mathbf{X})$.

Tabel 2. Hasil pengujian robot dalam mendeteksi dan menghindari furnitur

\begin{tabular}{|c|c|c|c|c|c|c|c|c|c|c|c|c|}
\hline & & & \multicolumn{10}{|c|}{ Percobaan Ke- } \\
\cline { 5 - 12 } No & Room & Daerah & 1 & 2 & 3 & 4 & 5 & 6 & 7 & 8 & 9 & 10 \\
\hline 1 & 1A & 1 & X & $\checkmark$ & $\checkmark$ & $\checkmark$ & $\checkmark$ & $\checkmark$ & $\checkmark$ & $\checkmark$ & $\checkmark$ & X \\
\hline 2 & 1B & 1 & $\checkmark$ & $\checkmark$ & $\checkmark$ & $\checkmark$ & $\checkmark$ & $\checkmark$ & $\checkmark$ & $\checkmark$ & $\checkmark$ & $\checkmark$ \\
\hline 3 & 2 & 1 & $\checkmark$ & $\checkmark$ & $\checkmark$ & $\checkmark$ & $\checkmark$ & $\checkmark$ & $\checkmark$ & $\checkmark$ & $\checkmark$ & $\checkmark$ \\
\hline 4 & 3 & 1 & $\checkmark$ & $\checkmark$ & X & $\checkmark$ & $\checkmark$ & $\checkmark$ & $\checkmark$ & $\checkmark$ & $\checkmark$ & X \\
\hline 5 & 4 A & 1 & $\checkmark$ & $\checkmark$ & $\checkmark$ & $\checkmark$ & $\checkmark$ & $\checkmark$ & X & $\checkmark$ & $\checkmark$ & $\checkmark$ \\
\hline 6 & $4 \mathrm{~B}$ & 1 & $\checkmark$ & X & $\checkmark$ & $\checkmark$ & $\checkmark$ & $\checkmark$ & $\checkmark$ & $\checkmark$ & $\checkmark$ & $\checkmark$ \\
\hline 7 & 1A & 2 & $\checkmark$ & $\checkmark$ & $\checkmark$ & $\checkmark$ & X & $\checkmark$ & $\checkmark$ & $\checkmark$ & $\checkmark$ & X \\
\hline 8 & 1B & 2 & $\checkmark$ & $\checkmark$ & $\checkmark$ & $\checkmark$ & $\checkmark$ & $\checkmark$ & $\checkmark$ & $\checkmark$ & $\checkmark$ & $\checkmark$ \\
\hline 9 & 2 & 2 & X & $\checkmark$ & $\checkmark$ & $\checkmark$ & $\checkmark$ & $\checkmark$ & $\checkmark$ & $\checkmark$ & $\checkmark$ & X \\
\hline 10 & 3 & 2 & $\checkmark$ & $\checkmark$ & X & $\checkmark$ & $\checkmark$ & $\checkmark$ & $\checkmark$ & $\checkmark$ & $\checkmark$ & $\checkmark$ \\
\hline 11 & 4 A & 2 & $\checkmark$ & $\checkmark$ & $\checkmark$ & $\checkmark$ & $\checkmark$ & $\checkmark$ & X & $\checkmark$ & $\checkmark$ & $\checkmark$ \\
\hline 12 & $4 \mathrm{~B}$ & 2 & $\checkmark$ & X & $\checkmark$ & $\checkmark$ & $\checkmark$ & $\checkmark$ & $\checkmark$ & $\checkmark$ & $\checkmark$ & $\checkmark$ \\
\hline
\end{tabular}


Untuk pengujian robot masuk dari pintu 1B, robot berhasil dengan baik mendeteksi furnitur dan melakukan follow yang sesuai. Begitu juga dengan furnitur pada room 2 dapat terdeteksi dengan baik. Pada pengujian daerah 2 , robot masuk dari pintu 1B berhasil dengan baik mendeteksi furniture dan melakukan follow yang benar.

Pada pendeteksian furnitur daerah 1 pada room 1A robot gagal sebanyak 2 kali dalam melakukan tugasnya. Hal ini dikarenakan ketika memasuki room robot gagal untuk memposisikan diri sehingga posisinya miring, ini menyebabkan robot tersangkut ketika melakukan scanning. Kesalahan yang sama juga menjadi penyebab robot gagal 1 kali mendeteksi furnitur pada room 3, 4A, dan 4B.

Kegagalan mengenali room juga menjadi penyebab robot tidak dapat mendeteksi furnitur. Hal ini terjadi 2 kali ketika robot berada pada room 3 dan terjadi masing masing 1 kali ketika robot berada pada room dengan pintu 4A (menghadap atas) dan pintu 4B (menghadap bawah).

Berdasarkan percobaan - percobaan di atas dapat dibuat ringkasan tingkat keberhasilan sebagai berikut. Pada pengujian untuk mendeteksi boneka, robot gagal 1 kali dari 60 kali percobaan sedangkan pada pengujian robot untuk memilih rute home yang tepat, robot gagal 4 kali dari 60 kali percobaan. Dengan demikian tingkat keberhasilannya berturut - turut $98.3 \%$ dan $93.3 \%$. Pada pengujian untuk mendeteksi furnitur, robot gagal 13 kali dari 120 kali percobaan, jadi tingkat keberhasilannya $89.2 \%$.

\section{Kesimpulan}

Berdasarkan perancangan, perealisasian dan pengujian yang telah dilakukan dapat ditarik kesimpulan sebagai berikut.

1. Penggunaan 8 sensor jarak ultrasonik yang disusun membentuk oktagon dengan metode scanning efektif mendeteksi furnitur di map KRPAI, dengan persentase keberhasilan $89.2 \%$.

2. Penggunaan 2 sensor proksimitas inframerah yang diletakkan sejajar pada jarak $11.5 \mathrm{~cm}$ dengan metode triangulasi efektif untuk mendeteksi boneka di map KRPAI dengan persentase keberhasilan $98.3 \%$.

3. Metode penandaan letak boneka efektif untuk mencegah robot bertemu boneka pada perjalanan menuju home, dengan persentase keberhasilan $93.3 \%$.

\section{Daftar Pustaka}

[1] B. Mustapha, A. Zayegh, and R. K. Begg, "Ultrasonic and Infrared Sensors Performance in a Wireless Obstacle Detection System," 2013.

[2] K. V. M. V. S. Praveen, "Obstacle Detection and Avoidance Autonomous Car," vol. 9, no. 15, pp. 783-790, 2014.

[3] D. Radaković and D. Cvetković, "Implementing Decision-Making Methods Based on Multipe Neural Networks," Proc. 1st Int. Sci. Conf. - Sint. 2014, pp. 931-936, 2014. 
